\title{
Anorectal functional disorders: towards a better diagnosis and treatment
}

Saad RC. Anorectal functional disorders: towards a better diagnosis and treatment. Arq Gastroenterol. 2019;56(1):1-2.

The diagnosis of functional disorders in colorectal surgery has gained more and more tools in order to understand the underlying physiologic and anatomic changes responsible for these symptoms. Incontinence and constipation are the leading complains in this area, each one with its particular subgroups (obstructed defecation, slow transit constipation, incontinence in various levels, etc.).

Selecting patients according to the history, physical and proper tests are the keys to obtain better results.

In this editorial I will present three papers that addresses these issues.

In the first paper, Pinto RA et al. ${ }^{(1)}$ compare the reliability of digital rectal examination (DRE), as compared to anorectal manometry (ARM), in accessing anal sphincter function. As outlined by the authors, DRE performed by the colorectal surgeon is a different exam then the DRE performed by the urologist to evaluate the prostate or before colonoscopy. The specialist should evaluate static and dynamic activities of the sphincter during resting, squeeze and valssalva maneuver.

Many papers have shown a good relation between DRE and ARM for resting and squeeze pressures, when accessing incontinent patients as compared to controls and/or constipated, and during attempted defecation in regarding Puborectalis activity ${ }^{(2,3,4)}$. Another publication by Soh JS et al. ${ }^{(5)}$ did not show a good relation between high resolution manometry in resting pressures when compared to DRE. Another limitation of DRE was found in identifying sphincter defects with less than 90 degrees, as shown by Dobben AC et al. ${ }^{(6)}$.

An interesting aspect of the study published in this issue of Arquivos de Gastroenterologia is the difference found in the accuracy of DRE when comparing senior vs junior examiner, a finding that has to be taken in consideration when using DRE as a selecting criteria to indicate ARM or specific treatment protocol. DRE can substitute ARM where this test is not available, but ARM remains the gold standart for anal sphincter function assessment, and is not operator dependent.

Despite the fact that DRE is usually a well tolerated test for the patients, in some instances, like pediatric patients, it might not be the case. Some times the physician may face a refusal of the parents to allow a rectal examination in their child. In this cases, other not invasive ways to evaluate constipation in children might be necessary, as stated by Momeni $\mathrm{M}$ et al. ${ }^{(7)}$ in the next paper presented. The authors point out that, in pediatric patients, even the history can be disappointing in providing useful information.

Although controversial, many studies show that a simple non-invasive procedure, without any preparation, can give the examiner some clue about the symptoms a child presents, with a good sensitivity and specificity, using an abdominal ultrasound to measure rectal diameter and rectal wall thickness.

The third paper by Murad-Regadas SM $^{(8)}$ evaluated prospectively the outcome of biofeedback (BF) treatment for fecal incontinence.

The European Society for Neurogastroenterology \& Motility (ESNM) and American Neurogastroenterology and Motility Society (ANMS) published in may/2015(9) its consensus about the use of $\mathrm{BF}$ to treat patients with functional disorders. The degree of evidence and recommendation for constipated patients was rated Level 1 Grade A, but for incontinent patients was rated Level 2, Grade B.

The study of Murad-Regadas SM et al..$^{(8)}$, as in the study of Terra MP et al. ${ }^{(10)}$, analyzed the results of BF treatment for incontinent patients, looking for prognostic factor that my influence results. It is also suggested that a faster track might be used in the up scaling of treatment for this patients, rising the question: should bad prognoses patients be submitted to a full, time and cost consuming, BF protocol to achieve a frustrating result, in this often depressed patients, or should they start a different approach to achieve a better chance of response?

Certainly, more studies should evaluate the treatment protocols for incontinent patients, looking for a more individualized approach.

Renato Caram SAAD*

* Ex-Fellow Cleveland Clinic, Ohio, EUA. Associado da Sociedade Brasileira de Coloproctologia. Membro titular da Sociedade Brasileira de Motilidade Digestiva. Diretor Clínica Saad Motilidade Digestiva, São Paulo, SP, Brasil. Orcid: 0000-0002-0915-0860. 
Saad RC. Alterações da função anorretal: caminhos para melhor diagnóstico e tratamento. Arq Gastroenterol. 2019;56(1):1-2.

\section{REFERENCES}

1. Pinto RA, Corrêa Neto IJF, Nahas SC, Froehner Junior I, Soares DFM, Cecconello I. Is the physician expertise in digital rectal examination of value in detecting anal tone in comparison to anorectal manometry? Arq Gastroenterol. 2019;56:79-83.

2. Favetta U, Amato A, Interisano A, Pescatori M. Clinical, manometric and sonographic assessment of the anal sphincters. A comparative prospective study. Int J Colorectal Dis. 1996;11:163-6.

3. Buch E, Alós R, Solana A, Roig JV, Fernández C, Díaz F. Can digital examination substitute anorectal manometry for the evaluation of anal canal pressures? Rev Esp Enferm Dig. 1998;90:85-93.

4. Hill J, Corson RJ, Brandon H, Redford J, Faragher EB, Kiff ES. History and examination in the assessment of patients with idiopathic fecal incontinence. Dis Colon Rectum. 1994;37:473-7.

5. Soh JS, Lee HJ, Jung KW, Yoon IJ, Koo HS, Seo SY, et al. The diagnostic value of a digital rectal examination compared with high-resolution anorectal manometry in patients with chronic constipation and fecal incontinence. Am J Gastroenterol. 2015;110:1197-204
6. Dobben AC, Terra MP, Deutekom M, Gerhards MF, Bijnen AB, Felt-Bersma $\mathrm{RJ}$, et al. Anal inspection and digital rectal examination compared to anorectal physiology tests and endoanal ultrasonography in evaluating fecal incontinence. Int J Colorectal Dis. 2007;22:783-90.

7. Momeni M, Momen-Gharibvand M, Kulouee N, Javaherizadeh H. Ultrasonography in determining the rectal diameter and rectal wall thickness in children with and without constipation: a case-control study. Arq Gastroenterol. 2019;56:84-7.

8. Murad-Regadas SM, Regadas FSP, Regadas Filho FSP, Mendonça Filho JJ, Andrade Filho RS, Vilarinho AS. Predictors of unsuccessful of treatment for fecal incontinence biofeedback for fecal incontinence in female. Arq Gastroenterol. 2019;56:61-5

9. Rao SSC, Benninga MA, Bharucha AE, Chiarioni G, Di Lorenzo C, Whitehead WE. ANMS-ESNM Position Paper and Consensus Guidelines On Biofeedback Therapy for Anorectal Disorders. Neurogastroenterol Motil. 2015;27:594-609.

10. Terra MP, Deutekom M, Dobben AC, Baeten CGMI, Janssen LWM, Boeckxstaens GEE, et al. Can the outcome of pelvic-floor rehabilitation in patients with fecal incontinence be predicted? Int J Colorectal Dis. 2008;23:503-11. 